\title{
O brincar como diálogo/pergunta e não como resposta à prática pedagógica
}

\author{
Heloisa dos Santos Simon* \\ Elenor Kunz**
}

\begin{abstract}
Resumo: O presente texto traz uma abordagem de fundamentação pedagógica sobre a relação entre o mundo de movimento da criança e a imaginação, e como essa relação pode ser transpassada para o ensino. Elementos da natureza, atividades com estórias, brincadeiras de faz de conta, atividades de circo e contação de histórias fomentam a liberdade, a vivacidade e a riqueza da imaginação no brincare-se-movimentar. Assim focamos no que é primordial, nos elementos primários que nos levam ao Ser do ser humano, à sua consciência, ao outro, à arte, à natureza e à vida.
\end{abstract}

Palavras-chave: Movimento. Criança. Imaginação.

\section{INTRODUÇÃo}

O presente texto é resultado de uma investigação teórica sobre fundamentos pedagógicos da relação entre o mundo de movimento da criança e a fluidez da imaginação, e como esta relação pode ser transpassada pela prática pedagógica de Educação Física ${ }^{1}$.

$\mathrm{Na}$ literatura voltada à Educação Infantil muito se fala sobre o lúdico e a brincadeira, porém de maneira muitas vezes já esquematizada e fechada: com formas pré-definidas de movimento; com início e fim de atividades pré-estabelecidas; sem espaço, tempo e liberdade para outras possibilidades de movimento. Utilizam circuitos fechados, sem espaço para criação ou expressão pela criança e são montados de modo a direcionar e controlar o movimento delas.

\footnotetext{
"Programa de Pós-Graduação em Educação Física. Centro de Desportos .Universidade Federal de Santa Catarina, Florianópolis, SC, Brasil. E-mail: heloisa_simon@hotmail.com

"Programa de Pós-Graduação em Educação Física. Centro de Desportos. Universidade Federal de Santa Catarina, Florianópolis, SC, Brasil. E-mail: elenkunz@terra.com.br>

${ }^{1}$ Esse texto é proveniente de dissertação de mestrado apresentada ao Programa de PósGraduação em Educação Física da Universidade Federal de Santa Catarina.
} 
Discussões com variadas abordagens e proposições têm sido disseminadas na Educação Infantil, porém, nos focamos na necessidade de estudos sobre a criança que se-movimenta e que, através do brincar, se relaciona e dialoga com o mundo (KUNZ, 2009). Essa relação dialógica da criança com o mundo que acontece através do movimento, no que compete à Educação da criança pequena, demanda muito mais do que o ensino - requer cuidado e envolvimento, brincadeira, arte e sentimento.

Quando nos focamos na imaginação da criança, nosso objetivo é redescobrir esse caminho da fantasia que parece perdido entre tantas teorizações e racionalizações excessivas de concepções pedagógicas que veem o brincar somente como instrumento para o desenvolvimento da criança com vistas a competências futuras tanto em relação ao esporte como ao trabalho. Essas concepções geralmente objetivam padrões de movimento pré-estabelecidos, atividades fechadas e habilidades padronizadas.

Desviar-nos dessa forma de 'ver' a criança nos aproximou dos estudos com referência fenomenológica e do conceito de 'brincare-se-movimentar', na busca por uma melhor compreensão dos fenômenos intuitivos e da consciência da criança pequena. Por isso, buscamos referência na cunhada 'teoria do se-movimentar', disseminada no Brasil por Elenor Kunz, que vem buscando estudar o ser-no-mundo através de uma concepção dialógica de movimento humano, com apoio na fenomenologia. $\mathrm{O}$ autor critica o enfático direcionamento biomecânico e fisiológico do ensino-aprendizagem de movimento nas escolas e enfatiza que o processo educativo deve tratar também das significações e intencionalidades do mundo de movimento, as quais são 'modos' de expressividade humana e experiências de ser-no-mundo.

\section{ENTRANDO NO MUNDO DA IMAGINAÇÃO}

A imaginação é considerada por Husserl (2006) como um ato dinâmico, livre e criativo de intencionalidade. É um modo único, constitutivo de consciência. Husserl (2006) afirma que a percepção 
é a principal e mais vantajosa forma de presentificação das coisas. Porém, alguns elementos da vivência, de ser real podem limitar, de certa maneira, as possibilidades da essência de alguns fenômenos ao serem experienciados. Como, por exemplo, o sentimento de voar, experienciado rapidamente em um salto com vara. Através da imaginação, muitas crianças que não conseguiriam executar corretamente o movimento que leva a essa experiência podem sentir algo aproximado do sentimento e sensação de voar. A experiência pode não ser real, mas o sentimento derivado dessa experiência fantasiosa passa a existir, ser real. E assim uma experiência impossível é tornada possível, apreendida pela sua essência.

Husserl (2006) explica que, para chegar à essência das coisas e conhecê-las verdadeira e inteiramente, seria necessário conhecer todos os tipos e variações dessa mesma coisa. E não existem essências por traz das aparências como muitas vezes é comentado quando se trata de entendimentos de fenomenologia. O próprio Husserl já comentava que as aparências já são essências, ou de outra forma também sua essência. Assim no caso de uma cerejeira vista no jardim, não existe uma cerejeira no jardim e outra na consciência da pessoa que a vê. O que existe é a cerejeira e sua essência que não precisa sempre existir concretamente na minha frente, mas pode existir no meu imaginário apenas como essência. Por isso, é impossível observar todas as cerejeiras existentes e apreender o que há nelas de invariável, portanto a tarefa da variação fica, de certa forma, presa ao imaginário. Só é possível através da imaginação, que excede as possibilidades permitidas pelo empírico, extrapolando a realidade efetiva e conduzindo a uma estrutura de possibilidade que nos habita (DEPRAZ, 2008).

Para explanar melhor como essa extrapolação através da imaginação acontece, Husserl segue explicando com outro exemplo - o do desenho de um geômetra.

Na imaginação, naturalmente, ele tem de se esforçar para obter intuições claras, esforço de que o desenho e o modelo o poupam. Mas no desenho e no modelo efetivos ele fica atado, ao passo que na imaginação ele tem a liberdade inigualável de reconfigurar como 
quiser as figuras fictícias, de percorrer as formas possíveis em contínuas modificações e, portanto, de gerar um sem-número de novas construções; uma liberdade que the franqueia acesso às imensidões das possibilidades eidéticas, com seus horizontes infinitos de conhecimentos de essência (HUSSERL, 2006, p. 153).

Podemos fazer uma relação direta com as atividades educativas, nas quais, se já dadas ou fechadas com roteiros - início, meio e fim, a criança fica 'atada' quanto ao desenvolvimento de outros movimentos e possibilidades. Isso acontece muito em aulas de Educação Física em que as crianças são, literalmente, colocadas para percorrer um circuito fechado de atividades motoras, as quais nem entendem o que ou porque estão fazendo. Husserl sugere a superioridade de atividades livres ${ }^{2}$ que deixam fluir a imaginação e que abrem possibilidades para a criança fazer de seu jeito, de outro jeito além do comumente realizado, de modo que a criança possa descobrir novas maneiras de se-movimentar para ampliar os horizontes de habilidades e seu mundo de vida.

$\mathrm{Na}$ fantasia do jogo e da brincadeira, a criança tem a liberdade de percorrer o caminho que quer e precisa a fim de chegar ao final escolhido ou aproximado para ter uma experiência de sucesso na atividade. Não há limitações quanto à forma, mas sim novas possibilidades ao percorrer o tapete do ato, o poder escolher o lado para arremessar à cesta, e não ficar limitado devido à posição tática na equipe. $\mathrm{O}$ mais importante é essa abertura, essa possibilidade aberta e não fechada, como em atividades e movimentos fixos, pois o movimento requer abertura, possibilidade, escolha.

Porém as afirmações de Husserl não direcionam para simplesmente deixarmos as crianças livres sem nenhuma orientação, para que aprendam as coisas sozinhas. Pelo contrário, Husserl (2006, p. 154) fala que é necessário "fertilizá-la mediante observações as

\footnotetext{
${ }^{2} \mathrm{O}$ uso de termos como livres e espontâneos são no sentido de movimentos não somente delimitados e com propósitos externos, mas que são, primariamente, desenvolvidos a partir da expressividade própria da pessoa. Tem uma noção diferente de espontaneísmo. É relacionado ao diálogo ativo, original e expressivo do ser-no-mundo.
} 
mais ricas e boas possíveis na intuição originária". E cita a história, a arte e a poesia como fontes proveitosas e sugestivas para apreensões compreensivas do mundo.

Nesse sentido, Girardello (2011, p. 76) também orienta para a importância de experiências imaginativas não somente em atividades artísticas e estéticas, mas "em seu processo integral de conhecimento do mundo, tanto em seus aspectos estéticos quanto científicos". Estamos salientando essa forma de aprendizagem que parece ter sido esquecida ou suprimida pela excessiva racionalização do conhecimento.

As experiências imaginativas, a fantasia e o sonho também modificam as nossas percepções e relações com o mundo, os outros e conosco mesmo. Fisiologicamente, podemos exemplificar pela criança que sonha que vai ao banheiro e faz xixi na cama, pois imagina, sonha estar lá, e o corpo responde fisiológica e emocionalmente à fantasia, como se fosse real e tivesse acontecido. Esse é um exemplo claro de modificações nas vivências, no mundo de vida da criança, modificações fortes como sensações e percepções, porém causados somente pela imaginação e que podem levar a outro nível de conscientização.

Quanto a essas modificações causadas no mundo de vida da criança, é importante nunca esquecer que cada criança é individual e assim também são suas memórias, mundos de vida, e as relações também serão estabelecidas de forma diferente, variando de criança para criança. Portanto, cada criança levada a fantasiar e memorizar movimentos, brincadeiras e gestos, fará suas próprias relações e, com isso, diferentes movimentos serão executados partindo de um mesmo estímulo, como ultrapassar uma corda, pois para cada criança a corda será algo diferente e requisitará outra resposta para ultrapassá-la. Assim, algumas crianças rastejarão para passar pela corda, outras pularão com os dois pés, outras pularão com um pé de cada vez, mas todas ultrapassarão a corda, como a atividade pede.

Essa 'pedagogia da imaginação', como podemos aproximar do que Ítalo Calvino (2010) apresentou, também leva a criar 
possibilidades, situações e ambientes de estímulo às capacidades potenciais das crianças. Ela conduz não só a movimentos prédefinidos curricularmente, mas também a ambientes completos e efetivos, que abrem as portas para a criança querer dar o próximo passo sozinha. Enfim, possibilitam situações que levam a criança a descobrir as coisas por si mesma, com tudo o que ela tem a oferecer, e por intermédio do que já conhece e de caminhos que possibilitamos a ela.

Disponibilizar diferentes lugares, materiais e possibilidades de movimentos parecem ser fatores essenciais para uma educação voltada à liberdade da imaginação e levam a muitas outras oportunidades e facilidades de apreensão de realidades, situações e fenômenos pelas crianças, não apenas para as aprendizagens formais da escola e sim para a vida. Encontra-se implícito nesse entendimento sobre a imaginação da criança o direito à vida que esta tem, ou seja, o direito de viver em liberdade e responsabilidade.

\section{A prática pedagógica}

Os Parâmetros Curriculares Nacionais para a Educação Infantil identificam as brincadeiras e as interações como eixos norteadores da prática pedagógica do professor da Educação Infantil (BRASIL, 2010). Esses eixos também visam garantir uma formação humana integral, orientada para as diferentes dimensões humanas - linguística, intelectual, expressiva, emocional, fisiológica, social, cultural e espiritual.

Faz-se necessário, portanto, durante a formação profissional, um trabalho de sensibilização dos futuros professores, visto que não é tão simples e fácil descobrir quais as potencialidades e as necessidades das crianças. É preciso compreender a intencionalidade que a criança apresenta na brincadeira, ler nas entrelinhas o diálogo com o mundo estabelecido através de uma brincadeira de bonecas, ou da expressividade exposta pela criança quando se nega a participar de alguma atividade ou algum lugar. Nesse sentido, Sayão (2002, p. 61) apontou que: "É necessário que as professoras sejam capazes 
de, empaticamente, fazer a leitura das linguagens infantis, colocandose disponíveis corporalmente, para compreenderem seus sentidos e significados."

Para isso, é fundamental que nos cursos de formação profissional os estudantes tenham acesso a conhecimentos ainda não muito aprofundados na área e que diz respeito à corporeidade e seus desdobramentos como a percepção, movimento humano e outras temáticas que envolvem cultura de movimento e contextos sociais e históricos da Educação e da Educação Física. A docência na Educação Infantil exige disponibilidade corporal primária para as crianças. O professor precisa estar ali, em contato direto com elas, fazendo com elas a atividade, em toda sua corporeidade, com todo seu ser. Pois as experiências são vividas por inteiro, pela corporeidade, pela consciência intuitiva que reina sobre todas as capacidades do ser humano (MERLEAU-PONTY, 2004).

Como traz Sayão (2002, p. 62),

[...] é preciso que conheçamos as possibilidades de nossos corpos: seus gestos, movimentos, expressões. Para tal, nos processos de formação das profissionais que atuam com as crianças pequenas, faz-se necessário incluir o olhar para nós mesmas, é preciso aprender a conhecer as reações de nossos corpos ao toque, à música, aos odores.

O processo educativo exige dedicação de tempo e atenção às brincadeiras e variações desenvolvidas pelas próprias crianças, atividades não direcionadas, mas escolhidas por elas mesmas para dialogar com o mundo e com os outros e consigo mesmas.

O imaginário da criança está sempre 'à flor da pele', em todos os momentos, quer sentada na mesa brincando com a comida, quer na hora de dormir, brincando com o cobertor e o escuro. Ela pode usar qualquer objeto para brincar e representar a estória que constrói e desenvolve em seu imaginário. Através dessas estórias inventadas, construídas e fantasiadas, a criança está desenvolvendo um 'diálogo' com o mundo, com algumas situações criadas e outras vividas. São situações que são imaginárias, fantasiadas pela criança, mas que 
expressam muitos sentimentos, anseios, preocupações, alegrias e sucessos reais para essa criança (OAKLANDER, 1980). Em algum momento, ela pode ter vivenciado ou visto essa situação, e através da brincadeira ela pode aprender e reelaborar a melhor maneira de lidar com isso, experienciando a situação através da imaginação e fantasia.

Observando e acompanhando o brincar-e-se-movimentar da criança, podemos 'ver mais de perto' e compreender melhor toda a expressividade que a criança apresenta na brincadeira. A maneira de nos inserirmos nesse 'mundo de fantasia' que é a brincadeira é, como dizem as crianças... entrando na brincadeira.

É assim que elas nos dizem o que querem dizer, isto é, se comunicam. É o movimento expressivo de um olhar, de um cheiro, de um calor, de um frio, de um tato que nos descentra (tira-nos do nosso próprio centro e nos leva a considerar o outro) e nos exige atitude e ação (SILVA, 2007, p. 64).

O professor de Educação Física geralmente tem uma formação mais voltada à ordem, à organização, à formação e à disciplina da criança. Porém, quando se trata de crianças pequenas, a liberdade é primordial para que ela possa se expressar, se-movimentar, devanear nas possibilidades da brincadeira. Para esses devaneios acontecerem, é preciso não tolher a liberdade da brincadeira, estimular variações e, sempre que possível, participar dos devaneios. Ou seja, brincadeiras com espaço e liberdade para a fantasia e imaginação permitem que a criança crie e desenvolva ações e relações individuais e coletivas com a situação, cenários e elementos imaginados, sendo então ressignificadas, obtendo um sentido e uma intencionalidade própria.

Geralmente, na rotina da creche, a brincadeira tem um objetivo pedagógico. Esse objetivo pode existir nas atividades direcionadas, porém é preciso permitir que a criança descubra por si própria o caminho, o como chegar lá. O objetivo principal na Educação Infantil deve, desta forma, expressar esta possibilidade de liberdade e espontaneidade da criança. Porém essa liberdade e espontaneidade da criança devem estar atreladas a descobertas. Às crianças devem 
ser dadas oportunidades de descoberta e, portanto, imposições e atividades fechadas são empecilhos para esta grande possibilidade pedagógica.

Por isso que se diz que a brincadeira deve ser diálogo e não resposta.

A verdadeira viagem da imaginação é a viagem ao país do imaginário, no próprio domínio do imaginário. Não entendemos por tal uma dessas utopias que nos dão de uma só vez um paraíso ou um inferno, uma Atlântida ou uma Tebaida. É o trajeto que nos interessaria, e o que nos descrevem é a estrada. Ora, o que queremos examinar nesta obra é na verdade a imanência do imaginário no real, é o trajeto contínuo do real ao imaginário. Poucas vezes se viveu a lenta deformação imaginária que a imaginação proporciona às percepções. Não se experimentou adequadamente o estado fluídico do psiquismo imaginante. Se pudéssemos multiplicar as experiências de transformações de imagens, compreenderíamos como é profunda a observação de Benjamin Fondane: 'A princípio, o objeto não é real, mas um bom condutor do real.' (BACHELARD, 2001, p. 5).

É fundamental manter a abertura das atividades, não 'podar' iniciativas e diferenciações que a criança venha a fazer, pois ela está experimentando as coisas e estabelecendo as relações e conclusões, que são aprendizados a partir das experiências. Porém, para isso é preciso que ela tenha a possibilidade de fazer diferente, que o desenho ainda não esteja traçado, que ela possa preenchê-lo e desenhar as formas, que possa descobrir as diferentes maneiras de rolar sozinha, não apenas sendo guiada pelas mãos da professora, mas que descubra o quanto seu corpo é capaz de contorcer e que o de seu colega pode ser mais ou menos flexível do que o seu, pois são diferentes, e que isso também faz parte da natureza de ser humano.

Para que essa aprendizagem possa acontecer, é necessário criar as condições adequadas para essas descobertas. É importante haver materiais e espaços próprios para as atividades e as 
possibilidades criadas, e que a criança tenha tempo para brincar e descobrir as diferentes formas de executar uma atividade até chegar ao objetivo final. Tudo isso precisa estar integrado ao planejamento das atividades docentes.

A racionalidade, a concordância dos espíritos não exigem que cheguemos todos à mesma ideia pelo mesmo caminho, ou que as significações possam ser encerradas numa definição, ela exige apenas que toda experiência comporte pontos de abertura a todas as ideias e que as 'ideias' tenham uma configuração. (MERLEAU-PONTY, 2012, p. 232).

Os professores "devem não só criar e exprimir uma ideia, mas ainda despertar as experiências que a enraizarão nas outras consciências" (MERLEAU-PONTY, 2004, p. 135), pois a atividade pode não trazer apenas o que o professor antecipou da experiência, mas proporcionar aprendizagens mais amplas, ou bem específicas ou diferenciadas, dependendo da costura entre o particular e o universal - o mundo vivido da criança e o que todos sentem ao viver a mesma vivência.

"É ainda chamando-o fala ou espontaneidade que melhor designaremos esse gesto ambíguo que produz o universal com o singular, e o sentido com nossa vida" (MERLEAU-PONTY, 2012, p. 237). Os movimentos espontâneos permitem toda a expressividade do movimento humano - a liberdade do movimento para expressar o que a criança está sentindo na atividade, nos estímulos, na interação de seu corpo com o mundo, com os colegas, com os animais e com a natureza.

Na pedagogia da educação infantil, as crianças e as interações que estabelecem entre si e com os adultos são o ponto de partida para a construção e reconstrução de uma cultura que está viva, é dinâmica, na qual o'corpo e o movimento', seus sentidos e significados são vistos e vividos como características especificamente humanas (SAYÃO, 2002, p. 65).

Como Sayão salienta, é fundamental manter na educação da criança pequena essas características e atendimentos a necessidades 
tão específicas desse nível de educação, que exige essa forma mais criativa e livre de aprendizado. Nessa, é necessidade primária que o professor traga estímulos, ambientes, materiais e acessos a novos conhecimentos e interações, e que a forma de aprendizagem desses não seja através de repetição monótona e cansativa.

Assim como a concepção aberta de movimento, existe um objetivo final, porém a jornada, a viagem (Erfahrung) da experiência é o real e significativo realizador da aprendizagem. É essa forma de movimento que propomos abordar na educação de crianças pequenas. É preciso, para a ampliação de seu mundo de movimento e para a realização de experiências realmente significativas para a criança, movimentos que tenham base intuitiva, assim como na intuição fenomenológica. A realização desse diálogo com o mundo, diálogo não imposto pelo professor, mas estimulado, conduz a criança a desenvolver uma relação de proximidade com o mundo e o desconhecido através da mediação pedagógica.

Por isso trazemos a imaginação como importante mediação dos primeiros contatos e aprendizagens da criança no mundo, pois a brincadeira imaginativa permite à criança estabelecer relações e compreensões que nem sempre, na realidade do mundo, acontecem.

A importância das brincadeiras de faz de conta e de fantasia é, muitas vezes, esquecida pelos professores que, a partir de uma visão escolarizada de atividades de Educação Física e até mesmo devido à sua formação pedagógica, acreditam que a brincadeira tem hora para começar e para terminar, que tem hora para a criança fantasiar, tem hora para apenas imitar, e ainda, hora para ficar quieta, pois tudo na "escola" tem que ter uma finalidade útil. Porém, a brincadeira da criança pequena não tem hora para acabar e nem para mudar de cenário. Quem observar uma criança brincando, pode perceber que ela pode mudar de personagem e de cenário a cada dois segundos, ou pode ficar até horas brincando do que parece ser a mesma coisa, sem extinguir as possibilidades e chamas daquele enredo.

Bachelard (2001, p. 8) sugere "uma lei das quatro imaginações materiais, lei que atribui necessariamente a uma imaginação criadora um dos quatro elementos: fogo, terra, ar e água". Ele faz descrições 
de orientação fenomenológica e poética dos quatro elementos da natureza como hormônios da imaginação. Acentua como os inúmeros elementos que a natureza traz podem contribuir com os elementos e capacidades envolvidas nas diferentes potencialidades humanas, possibilitando os caminhos para uma "sublimação especial" no brincar-e-se-movimentar (BACHELARD, 2001, p. 12).

$\mathrm{Na}$ educação com a natureza, é preciso ter cuidado para que a brincadeira não se torne completamente livre e sem intenção alguma, nem completamente fechada ou descontextualizada, apenas com propósitos externos à criança. De maneira geral, a natureza pode possibilitar que a criança desenvolva um mundo de reações e relações aos estímulos provocados pela interação. Assim, a criança não está "presa" em um roteiro de exercícios, mas tem como "estímulo" elementos que fazem parte de seu mundo de vida, um 'cenário' onde possa se situar, um guia que a conduza durante a 'viagem', a troca entre os elementos das diferentes 'viagens' que seus colegas fazem e, sobretudo, os sentimentos que a criança deixa aparecer na brincadeira. Esses são elementos estratégicos para o brincar.

A seguir são apresentadas algumas sugestões de elementos que envolvem a imaginação e fantasia:

a) Elementos da natureza

Atividades envolvendo a natureza podem ser desenvolvidas de diferentes maneiras e espaços. O ideal seria estar em um espaço aberto, com gramado, árvores, local com terra, e ainda um lago raso. Porém, a grande maioria de praças, parques e creches não tem tais locais disponíveis.

As atividades com terra, água e plantas são estimulantes espontâneos da brincadeira imaginativa e ainda permitem aprender mais sobre os fenômenos naturais. Exemplos de atividades com água: brincar de barquinho na poça d'água, descer um morrinho na chuva, ou apenas observar as diferentes intensidades da chuva, as cores, formas e as sensações despertadas pelas gotas d'água.

As brincadeiras com terra, areia ou barro possibilitam a representação de diferentes situações, onde muitas crianças 
representam o que veem no dia-a-dia, brincando de fazer "comidinha como a mamãe", de "carrinho como o papai" ou de "fazendinha com os bichinhos". Mas é importante a liberdade, a escolha da temática pela criança, sendo que a atividade servirá como estímulo e mediação da aprendizagem, e não como pura reprodução de situações sociais tradicionalmente estabelecidas.

O vento é abordado em muitas brincadeiras populares como a pipa, a bolinha de sabão, aviãozinho de papel, folhas e movimentos das árvores. Também podem ser abordadas as sensações provocadas pelo vento, como o frio, calor, etc.

O fogo geralmente é considerado muito perigoso, porém, se abordado com os devidos cuidados de segurança, as crianças podem aprender muitos saberes interdisciplinares. $\mathrm{O}$ adulto pode, inclusive, preparar algo para as crianças comerem numa fogueira, ou preaquecer alimentos para que as próprias crianças possam preparar.

b) Criar um contexto com cenário e estórias para as atividades

Atividades sem estória geralmente são consideradas 'chatas' e 'sem graça' pelas crianças pequenas. A atividade que parte de um contexto ou estória inicial geralmente é realizada com mais alegria, empenho e desembaraço pelas crianças.

É interessante não trazer uma estória já pronta, com início e fim determinados, mas permitir que as crianças possam construir a estória ou, ao menos, desenvolver, sugerir e modificar um pouco o caminho percorrido.

Muitas vezes, as brincadeiras que as crianças trazem de casa podem ajudar a definir um contexto. Por exemplo, uma casa de apoio em uma reforma/construção, que geralmente é de madeira, pode, no imaginário infantil, ser a casa de madeira do clássico conto dos Três Porquinhos, e assim virar temática de muitas brincadeiras.

As temáticas de atividades que as crianças estão desenvolvendo com outros professores ou em projetos coletivos também podem ser uma fonte rica de contextos para as brincadeiras. A integração e interdisciplinaridade das atividades e temáticas são muito 
recomendadas nas Diretrizes Curriculares Nacionais para a Educação Infantil (BRASIL, 2010).

c) Brincadeiras de faz de conta

Nas brincadeiras de faz de conta, as crianças personificam personagens e vivem situações que não acontecem em seu dia-adia. Com isso, desenvolvem habilidades, constroem relações míticas e sociais ainda desconhecidas e abrem o "tempo futuro e o campo dos possíveis" (CHAUÍ, 2000, p. 168).

É na brincadeira de faz de conta que as crianças estimulam as capacidades de sonhar, devanear e criar - relacionadas, sobretudo, com o pensamento abstrato e capacidades subjetivas. É importante não tolher tais capacidades, mas pelo contrário, oferecer elementos que estimulem a capacidade criativa nas brincadeiras de faz de conta. São atividades que criam oportunidades de transformação às crianças ao se comportarem como animais, personagens de contos, heróis e heroínas, entre outros.

As histórias infantis narradas em livros e vídeos, por pais e avós, são um verdadeiro tesouro para o imaginário infantil. As crianças usam essas histórias para brincar, sonhar e construir seu próprio imaginário social... Que as brincadeiras sugeridas por nós nunca deixem de fomentar tal imaginário.

d) Atividades circenses

No universo infantil o circo é sinônimo de magia para muitas crianças. As atividades circenses geralmente levam as crianças a experienciarem movimentos e sensações 'mágicas'. Virar uma estrelinha, fazer um rolinho, conseguir equilibrar-se em pernas de pau, ou harmonizar o jogo dos malabares geralmente resulta em um largo sorriso e um sentimento de sucesso.

Muitas habilidades e capacidades estão sendo estimuladas e desenvolvidas, porém a criança geralmente aparenta estar mais se divertindo do que realizando uma atividade física ou desenvolvendo habilidades psicossociais e motoras. Isso acontece devido ao contexto 'mágico' do circo. 
Para as crianças entrarem no clima da fantasia do circo, assistir vídeos de espetáculos diversos, convidar artistas circenses para realizar apresentações, ou mesmo quando possível, levá-las para apreciar um espetáculo, pode abrir muitas possibilidades para que as crianças desenvolvam o interesse pelas artes circenses, conhecendo um pouco mais sobre esse vasto e 'mágico' universo.

e) Contação de histórias

A contação de histórias permite que a criança devaneie em variadas realidades, tempos e lugares. Através da narrativa, vívidas imagens são formadas e 'criam vida' e enredo cultivados no imaginário. Essas estórias virtuais auxiliam no desenvolvimento dos sentidos e significados simbólicos de ações dos personagens, da situação, do enredo e, consequentemente, da criança ouvinte.

O narrador precisa deixar-se envolver pela fantasia da história, captando as essências e os sentidos 'invisíveis' dos personagens, dos cenários e dos enredos. Objetos, trajes, caras e bocas e interações com as crianças são bem vindas à contação de histórias, pois 'abrem' o campo da imaginação e da fantasia.

A utilização de temas e/ou de elementos da natureza na Educação Física não são inovadores, porém, pela indisponibilidade de acesso real à natureza, muitos professores parecem ter esquecido suas potencialidades.

Atentemos a essas possibilidades quando uma criança brincar na areia ou com lama, construindo castelos e caminhos, ou reagindo ao simples toque gelado da terra que a faz rir sozinha, pelas sensações experimentadas e lembradas. Na natureza, não há brincadeiras prontas e acabadas, mas inúmeras possibilidades de experiência e descoberta de sensações, movimentos e relações. Geralmente, na natureza, as crianças brincam durante horas a fio, sem perguntar o que fazer agora, estimuladas por diferentes sentidos como um todo e em todos os momentos.

Porém, poucas são as Instituições educativas que tem o privilégio de ter fácil acesso à natureza. $\mathrm{O}$ que podemos fazer é imaginar e fantasiar. Através da imaginação e fantasia, podemos 'viajar' com 
as crianças até Canela/RS e brincar junto a sequoias ou 'ir' até a África e rolar com macacos, e assim possibilitar um mundo de novos movimentos e experiências a elas.

Através da interação com ambientes e elementos da natureza, as crianças parecem ter vivências integrais, com verdadeiras experiências e envolvimento com a brincadeira. Essas não são experiências de segunda mão, e sim, experiências cheias e vivas (KANT, 2010). Atividades nas quais ela pode realmente transcender limites.

Com isso, a criança consegue realmente compreender as experiências intuitivas originais que vive ao se movimentar. Ela lembra o contato, o real aprendizado, a situação vivida. Consegue viver as relações estabelecidas através do movimento e avança quanto às suas potencialidades e as do mundo em que vive. Até porque a educação tem o intuito de formar não só quanto às habilidades voltadas ao mundo do trabalho, mas também quanto às características potenciais de cada um de nós. E para isso, como professores, é fundamental criarmos e deixarmos abertas as possibilidades de movimentos das crianças pequenas, pois assim como o crescimento de um galhinho de plantinha, que se podarmos ou amarrarmos, continuará crescendo, porém não em todo seu esplendor, também as crianças pequenas precisam da liberdade, vivacidade e riqueza da imaginação do brincar-e-se-movimentar para crescer e se desenvolver.

\section{Considerações FINAIS}

São as experiências cheias e vivas que o mundo da imaginação nos possibilita que trazemos para contribuir com uma prática pedagógica em estreita relação com o mundo da vida da criança. Um modo mais amplo e aberto de ver o brincar da criança, com ampliado potencial de liberdade e possibilidades.

É preciso compreender que a criança pequena percebe o mundo integralmente, de corpo inteiro, a partir de toda sua corporeidade, ou como diz o jargão popular - "de corpo e alma". 
Para que o movimento da criança venha a ser significativo ao brincar-e-se-movimentar, podemos disponibilizar diferentes e adequados lugares, materiais e possibilidades de movimentos que estimulem a criança a desembaraçar os conhecimentos intuitivos que traz consigo, e que vem relacionando com seu mundo da vida. Quando as situações são adequadas às aprendizagens, a intuição da criança parece abrochar e ela consegue realizar as atividades com melhor apreensão e fluidez das coisas, possibilitando assim experiências de sucesso à criança. Essa fluidez deve ocorrer em todas as aprendizagens de novos conhecimentos que a criança venha a ter.

Aprendizagens que, em um só ato, são apreendidas e ressignificadas intuitivamente. Porém essas aprendizagens não acontecem apenas corporalmente ou intelectualmente, como muitos processos educativos esperam. Ocorrem através da corporeidade que "une" o pensar, o agir e o sentir; ocorrem por meio da conduta, do movimento significativo como um todo. Esse ato de aprendizagem engloba diversos espectros do mundo da vida (KUNZ, 2001). Até por isso, cada criança é como é, diferente uma da outra, devido aos diferentes entrosamentos dessa complexa rede de elementos que forma o ser humano. Assim, para cada criança, essa ressignificação do mundo de movimentos pode acontecer de forma diferente, e isso exige diferentes possibilidades de realização do movimento.

Realizações de experiências de verdade, que nos passam e deixam marcas, com as quais realmente aprendemos, não somente decoramos. Experiências significativas que tocam nosso mundo da vida, que entrelaçam nossas redes de mundos relacionais, com bagagens históricas, singulares e universais. As quais levamos para o resto de nossa vida, para o nosso cotidiano, não apenas para momentos e atividades específicas ou dirigidas.

Nessas experiências, é muito mais simples do que parece acreditar no conto de fadas. É só se permitir e sentir acontecer. Todo professor de crianças pequenas precisa fazer esse esforço e se permitir vivenciar e compartilhar a fantasia, esse impossível que se torna possível no mundo da criança. 
Egan (2007, p. 34) denota que:

[...] ser imaginativo, então, não é ter uma função específica altamente desenvolvida, mas é ter capacidade aprimorada em todas as funções mentais. Não é, particularmente, algo distinto da razão, mas sim o que dá flexibilidade, energia e vivacidade à razão. Ela torna toda a vida mental mais significativa; faz a vida ser mais abundante.

Isso pode ser aplicado ao "vermos com os olhos" a possibilidade do brincar da criança, não apenas como meio para algo futuro, mas realmente considerarmos toda a expressividade e individualidade que é colocada pela criança na brincadeira. Poderemos observar a criança brincando e se movimentando e perceberemos - como Bachelard falou, "[...] a animação que o ser recebe quando se submete de corpo e alma aos ditames da imaginação aérea" (BACHELARD, 2001, p. 17); perceberemos a arte que engloba o movimento humano, esse modo criativo de brincar e aprender brincando. Por isso, é necessário que a educação infantil seja tratada como arte e não ciência, pois como aponta Husserl, a arte pode mostrar o verdadeiro mundo das ideias e das coisas.

A arte, assim como a natureza, nos conduz a esses lugares inexplicáveis da consciência. Precisamos fazer arte e sentir arte com maior frequência do que fazemos, pois faz parte da natureza humana brincar, acreditar, simplesmente ser e viver.

Mas para isso precisamos centralizar nosso processo educativo na criança, e não nas atividades que ela faz, não apenas naquilo que ela ainda não consegue fazer. Precisamos focar no que é primordial, nos elementos primários que nos levam ao Ser do ser humano, à sua consciência, ao outro, a arte, a natureza e a vida. 


\begin{abstract}
Playing as a dialogue/question and not as an answer to educational action

Abstract: This article aims to describe a theoretical and pedagogical approach about the relation between the child's world of movement and imagination, and how this relation can be trespassed by the pedagogical action. Nature, activities with stories, make-believe games, circus activities, and storytelling promote freedom, vivacity and richness of imagination in playand-self-movement. Thus we focus on primordial and primaries elements that lead us to Be human being consciousness, the other, art, nature and life.

Keywords: Movement. Child. Imagination.
\end{abstract}

Jugar como un diálogo/pregunta y no como una respuesta a la práctica pedagógica

Resumén: Este texto proporciona una perspectiva teórica y pedagógica sobre la relación entre el movimiento del mundo y la imaginación del niño, y cómo esta relación puede ser activada por la práctica pedagógica. Diálogo a través de la interacción con elementos de la naturaleza como cuentos, juegos de fantasía, las actividades de circo y narración de cuentos. Estos estimulan la libertad, la vitalidad y la riqueza de la imaginación en el brincar-y-si-movimientar. Así nos centramos en lo esencial de los elementos principales que nos llevan a Ser un ser humano, a su conciencia, el otro, el arte, la naturaleza y la vida.

Palabras-clave: Movimiento. Niño. Imaginación.

\section{REFERÊNCIAS}

BACHELARD, Gaston. $\mathbf{O}$ ar e os sonhos: ensaio sobre a imaginação do movimento. 2. ed.. São Paulo: Martins Fontes, 2001.

BRASIL. Ministério da Educação, Secretaria de Educação Básica. Diretrizes Curriculares Nacionais para a Educação Infantil. Brasília, 2010.

CALVINO, Italo. Seis propostas para o próximo milênio: lições americanas. Trad.: Ivo Barroso. 3.ed.. São Paulo: Companhia das Letras, 2010.

CHAUÍ, Marilena. Convite à Filosofia. São Paulo: Ed. Ática, 2000. Disponível em: http://www.fag.edu.br/professores/bau/FAG\%202012/Fonoudiologia\%20Filosofia/ Livro\%20Convite\%20A\%20FILOSOFIA\%20CHAUI.pdf. Acesso em: 10 abr. 2012.

DEPRAZ, Natalie. Compreender Husserl. 2. ed.. Petrópolis, RJ: Vozes, 2008. 
EGAN, Kieran. Por que a imaginação é importante na educação? In: FRITZEN, C.; CABRAL, G.S.(Org.). Infância: Imaginação e educação em debate. Campinas: Papirus, 2007. p. 11-37.

GIRARDELLO, Gilka. Imaginação: arte e ciência na infância. Pro-Posições, Campinas, v. 22, n. 2, p. 75-92, maio/ago. 2011.

HUSSERL, Edmund. Ideias para uma fenomenologia pura e para uma filosofia fenomenológica: introdução geral à fenomenologia pura. 2. ed.. Aparecida: Ideias \& Letras, 2006.

KANT, Immanuel. Crítica da Faculdade do Juízo. 2.ed. Rio de Janeiro: Forense Universitária, 2010.

KUNZ, Elenor. Educação Física: Ensino e Mudanças. 2. ed.. Ujuí: Unijuí, 2001.

KUNZ, Elenor. Esporte: uma abordagem com a fenomenologia. In: STIGGER, M. P.; LOVISOLO, H. (Org.) Esporte de rendimento e esporte na escola. Campinas: Autores Associados, 2009.

MERLEAU-PONTY, Maurice. O olho e o espírito. São Paulo: Cosac Naify, 2004.

MERLEAU-PONTY, Maurice. A prosa do mundo. São Paulo: Cosac Naify, 2012.

OAKLANDER, Violet. Descobrindo crianças: abordagem gestáltica com crianças e adolescentes. Trad.: George Schlesinger. São Paulo: Summus, 1980.

SAYÃO, Déborah T. Corpo e movimento: Notas para problematizar algumas questões relacionadas à educação infantil e à educação física. Revista Brasileira de Ciências do Esporte. Campinas, v. 23, n. 2, p. 55-67, jan./mar. 2002.

SILVA, Eliane Gomes. Educação (Física) Infantil: Se-Movimentar e Significação. 2007. 131 f. Dissertação (Mestrado) - Universidade Federal de Santa Catarina, Centro de Desportos, Programa de Pós-Graduação em Educação Física, Florianópolis, 2007.

Fonte financiadora: CAPES

Endereço para correspondência:

Heloisa dos Santos Simon

Rua Maria Eduarda, 526, AP. 301

Bairro Pantanal,

Florianópolis, SC

CEP: $88040-250$

Recebido em: 07-05-2013

Aprovado em: 06-12-2013

Movimento, Porto Alegre, v. 20, n. 01, p. 375-394, jan/mar de 2014. 